\title{
取鍋予熱装置燃焼効率の改善
}

坪井成明 $*$ ，石川浩義*

\section{Improvement of Combustion Efficiency of Ladle Preheater}

\author{
Shigeaki Tsuboi and Hiroyoshi Ishikawa
}

\section{Synopsis}

As social concern in environmental issues had been rising, Kyoto protocol on preventing global warming came into force on February 16, 2005. In the protocol, Japan was required to cut the greenhouse gasses by $6 \%$ compared to the year of 1990 during the five-year period of 2008-12.

Placing the environmental issues as one of the most important issues through our business activities from a cooperate social responsibility standpoint, we recognize that reducing $\mathrm{CO}_{2}$ emissions is our high priority task which should be achieved as early as possible. Pursuant to Voluntary Action Program for Environmental Protection by Steelmakers presented by the Japanese Iron and Steel Federation, we have been promoting various environmental activities to reduce $\mathrm{CO}_{2}$ emission by $10 \%$ compared to the year of 1990.

In the steelmaking shop of our main plant, Chita plant, electricity accounts for large percentage of energy consumption followed by fuels such as heavy oil and kerosene. As in the fig. 1, fuel cost for ladle preheater is $49.3 \%$ of total fuel cost in Chita steelmaking shop. Being the key factor of reducing the whole fuel cost, yet its fuel consumption had not been greatly improved.

Thanks to the introduction of regenerative burner on April 2005 and its optimization of combustion, fuel consumption of ladle preheater was improved. Outline of the improvements are described here.

\section{1. 緒言}

環境問題として地球温暖化防止対策に社会的関心が高 まる中, 2005 年 2 月 16 日京都議定書が発効され，日本は 温暖化ガスを 1990 年対比 2008 ～ 2012 年の間に 6 \% 削減 することを義務付けられた. 大同特殊鋼（以下，当社とい う)の事業活動において企業の社会的責任という点からも 環境問題への対応を最重要課題の一つとして位置付け, そ の中で $\mathrm{CO}_{2}$ 排出量削減を早急に解決しなければならない テーマと認識している.当社は日本鉄鋼連盟の自主行動計 画を受け, 全社で 1990 年対比 2010 年までに $\mathrm{CO}_{2}$ 排出量 $10 \%$ 削減の目標に向かいとりくんできている.

当社 知多製鋼工場におけるエネルギーコストは電力が 大きな割合を占めているが, その他に重油や灯油などの燃 料がある.Fig.1に示すように, そのうち取鍋予熱装置が燃

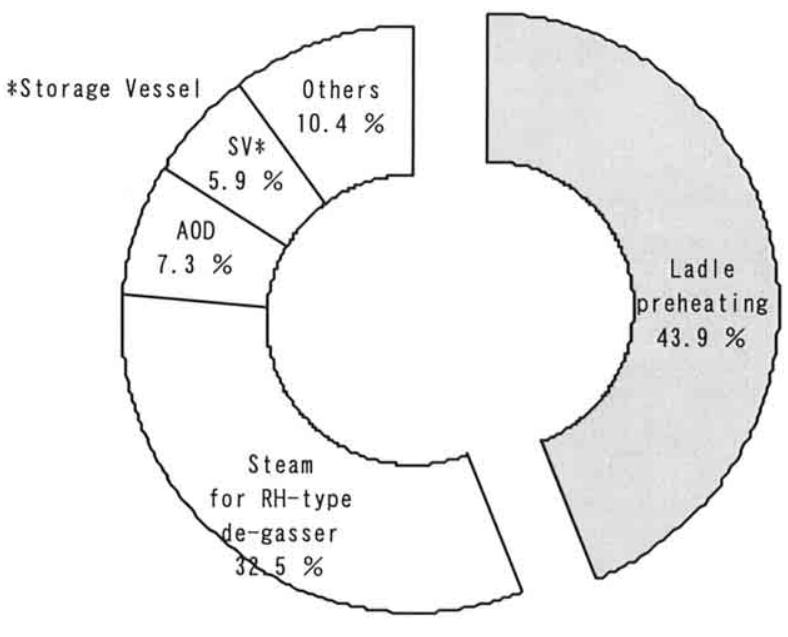

Fig.1. Fuel energy consumed at steelmaking shop. 
料コスト全体の 43.9 \%と大きな割合を占めており, コス 卜改善を図る上で重要なポイントとなっている.しかし取 鍋予熱装置の燃料原単位はこれまで大きな改善は着手さ れずに推移してきており, 燃焼方法や廃熱回収といった改 善の余地があった.そこで 2005 年4 月にリジェネバーナー の導入など燃焼改善を実施し，燃料使用量削減の改善を 行った. 以下に今回行った燃焼改善の概要および特徵につ いて述べる。

\section{2. 設備概要}

\section{1 設備レイアウト}

取鍋予熱装置の設備レイアウトを Fig.2 に示す. 取鍋予 熱装置は全部で 14 基あり，そのうち使用比率が特に高い 5 基を対象に燃焼改善を実施した。

\section{2 設備概要}

取鍋予熱装置の設備仕様を Table 1 に示す. 型式は縦型

Table 1. Specification of ladle preheater.

\begin{tabular}{l|l}
\hline \multicolumn{1}{c|}{ Type } & $\begin{array}{l}\text {-Vertical } \\
\text {-Top burner }\end{array}$ \\
\hline Ladle size & $\phi 3600 \mathrm{~mm} \times \mathrm{H} 3850 \mathrm{~mm}$ \\
\hline Burner capacity & $6.77 \times 10^{7} \mathrm{~J} / \mathrm{h}$ \\
\hline Fuel & Heavy oil \\
\hline Preheat temperature & Max. 1200 degrees $\mathrm{C}$ \\
\hline Preheat time & $\begin{array}{l}\text { Cold ladle }: 12 \mathrm{~h} / \text { ladle } \\
\text { Hot ladle }: 1 \mathrm{~h}, 6 \mathrm{~h} / \text { ladle }\end{array}$ \\
\hline
\end{tabular}

上部燃焼一方焚き, 被加熱物である取鍋は $\phi 3600 \mathrm{~mm} \times$ $\mathrm{H} 3850 \mathrm{~mm}$, バーナー容量は $6.77 \times 10^{7} \mathrm{~J} / \mathrm{h}$, 使用燃料は重 油, 予熱最大温度は $1200{ }^{\circ} \mathrm{C}$, 予熱並びに保熱時間は各取 鍋種類により 1 〜 12 時間である.

\section{3. 現状の取鍋予熱装置の問題点}

\section{1 燃料原単位の推移}

取鍋予熱装置の燃料原単位は Fig.3に示すように横ばい に推移している.そしてこれまで大きな改善は着手されて きておらず, 燃焼方法や廃熱回収といった改善の余地がある.

\section{2 設備の問題点}

Fig.4 に示すように，燃焼排ガス熱を再利用せずにその まま排出し燃焼エアーは冷風を使用するという燃焼効率

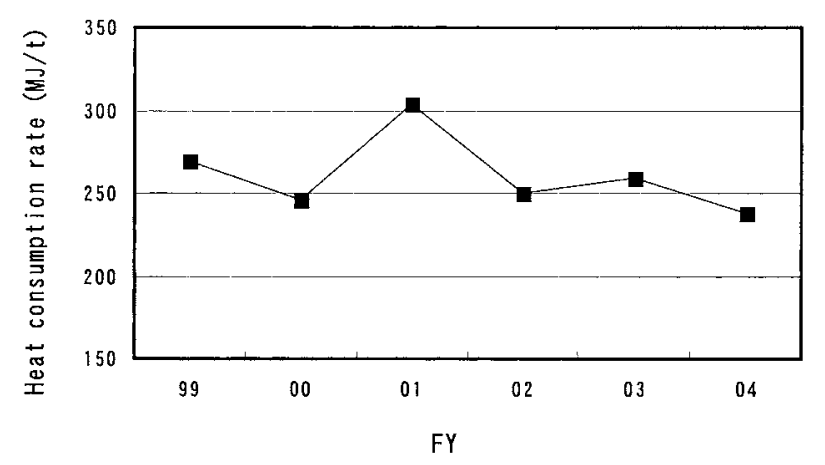

Fig.3. Fuel consumption of conventional ladle preheater.

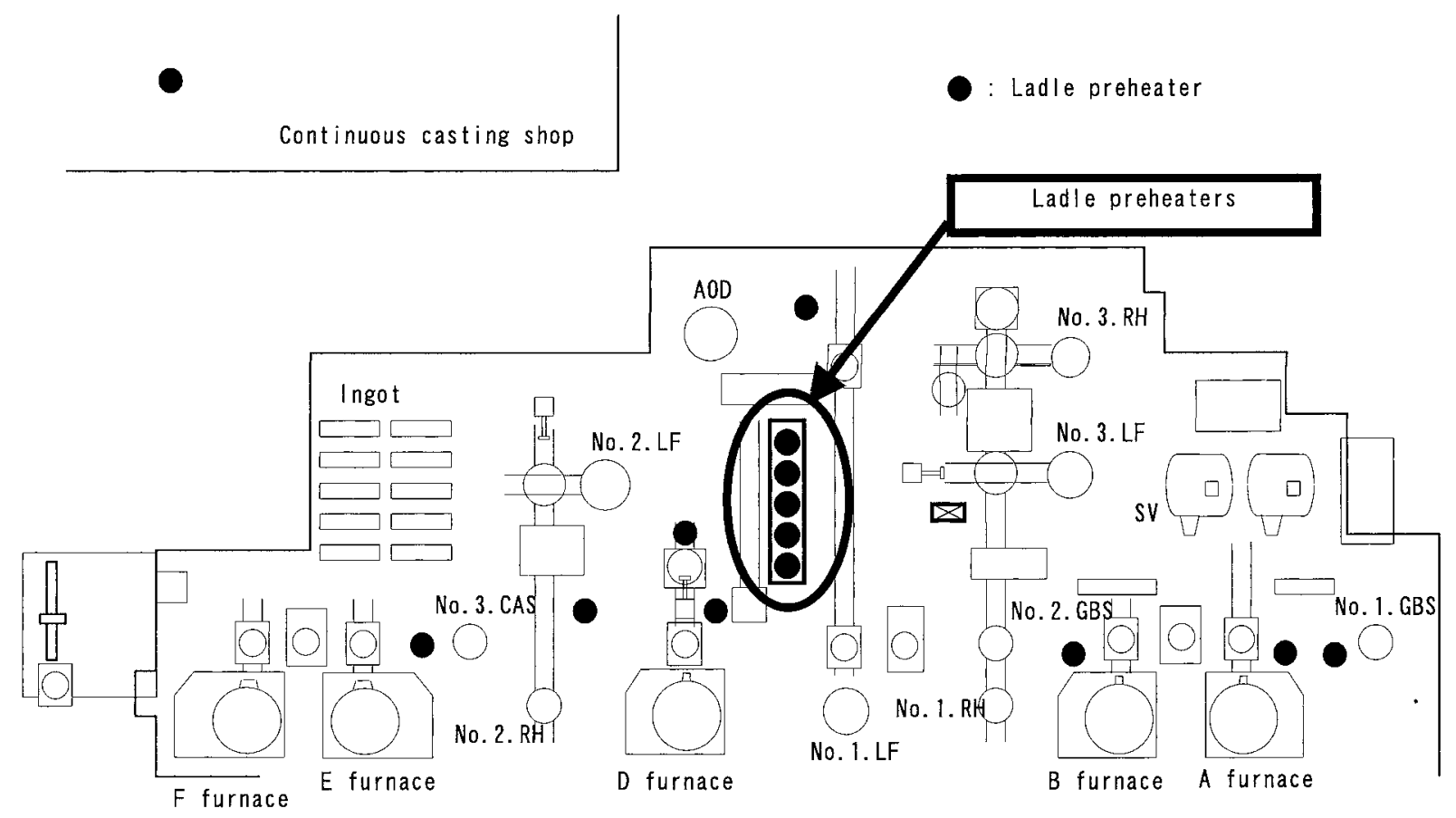

Fig.2. Layout of steelmaking shop / Position of ladle preheater. 


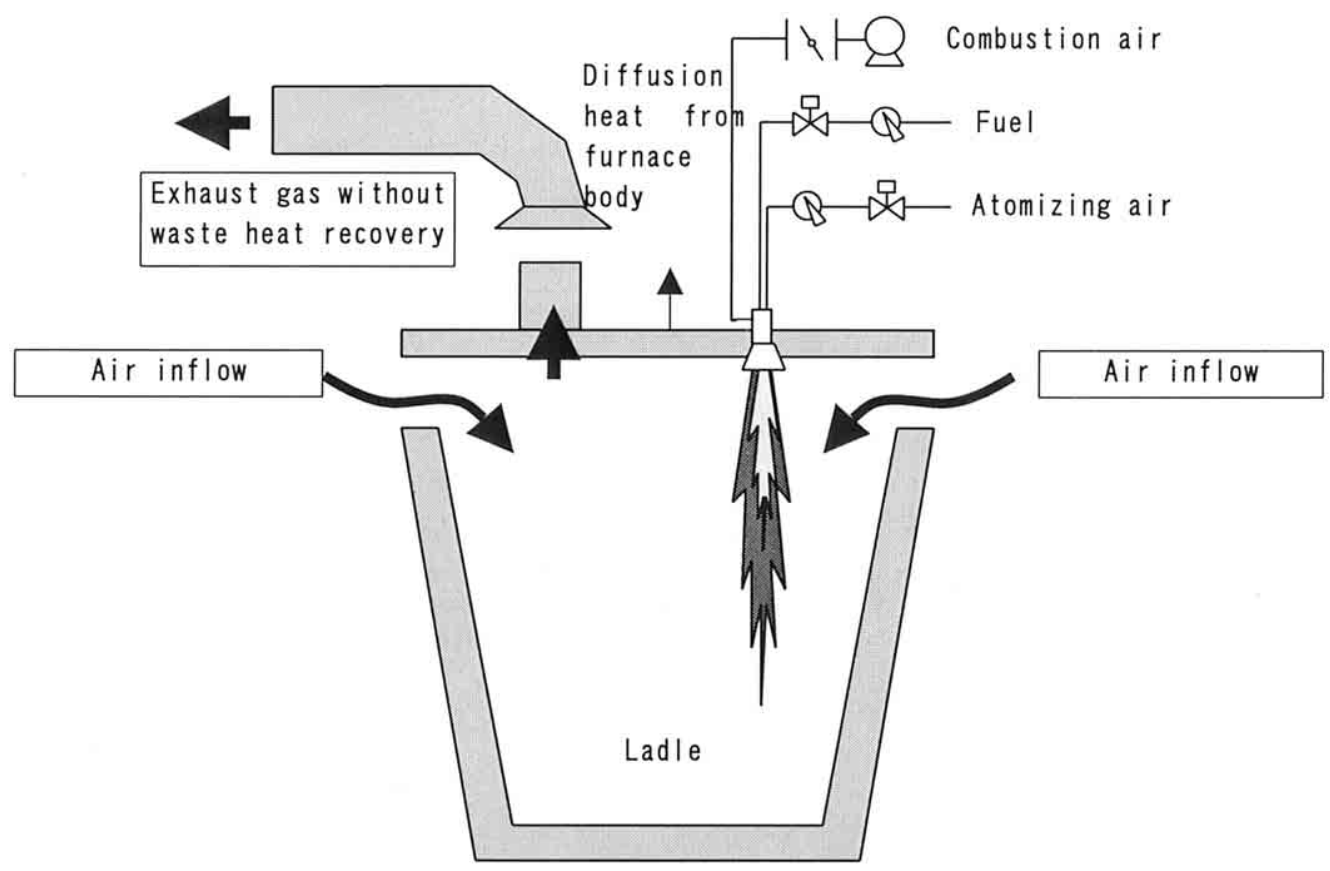

Fig.4. Cross-section drawing of ladle preheater.

Flow rate/temp. of I iquid fuel

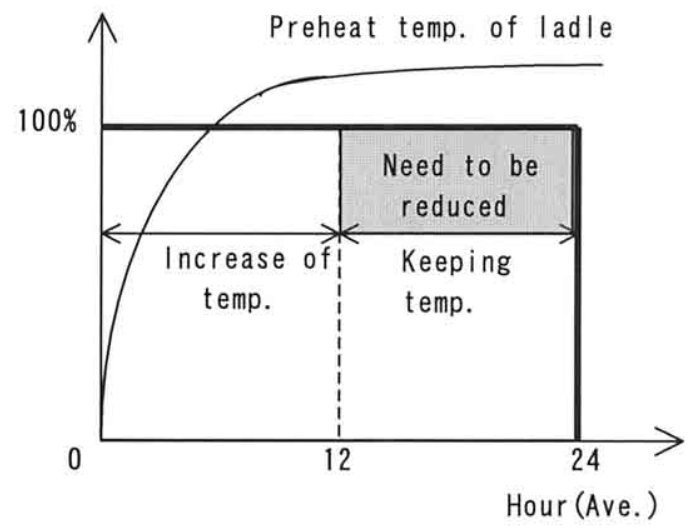

の悪い取鍋予熱を行っていた。また，Fig.5 に示すように 取鍋内温度が目標温度に到達しても昇熱時と同じ燃焼を 行い燃料の無駄が発生していた.そして取鍋予熱装置は取 鍋と予熱蓋の隙間が多く,そこからの侵入エアーによって 熱口スが発生している. 以上より, 燃料原単位の改善には 排ガス熱の再利用による燃焼エアーの予熱, 適切な燃焼調 整，そして侵入エアーによる熱ロスの低減が考えられる.

\section{3 熱精算結果}

従来の取鍋予熱装置において熱精算を実施したところ, Fig.6に示すように排ガス損失は $46.2 \%$, 予熱蓋隙間から の侵入エアーによる熱損失は $6.9 \%$ であり，これらを合計 すると燃料燃焼熱の約半分と大きな割合になる。

Fig 5. Combustion diagram of ladle preheater ( for cold ladle).

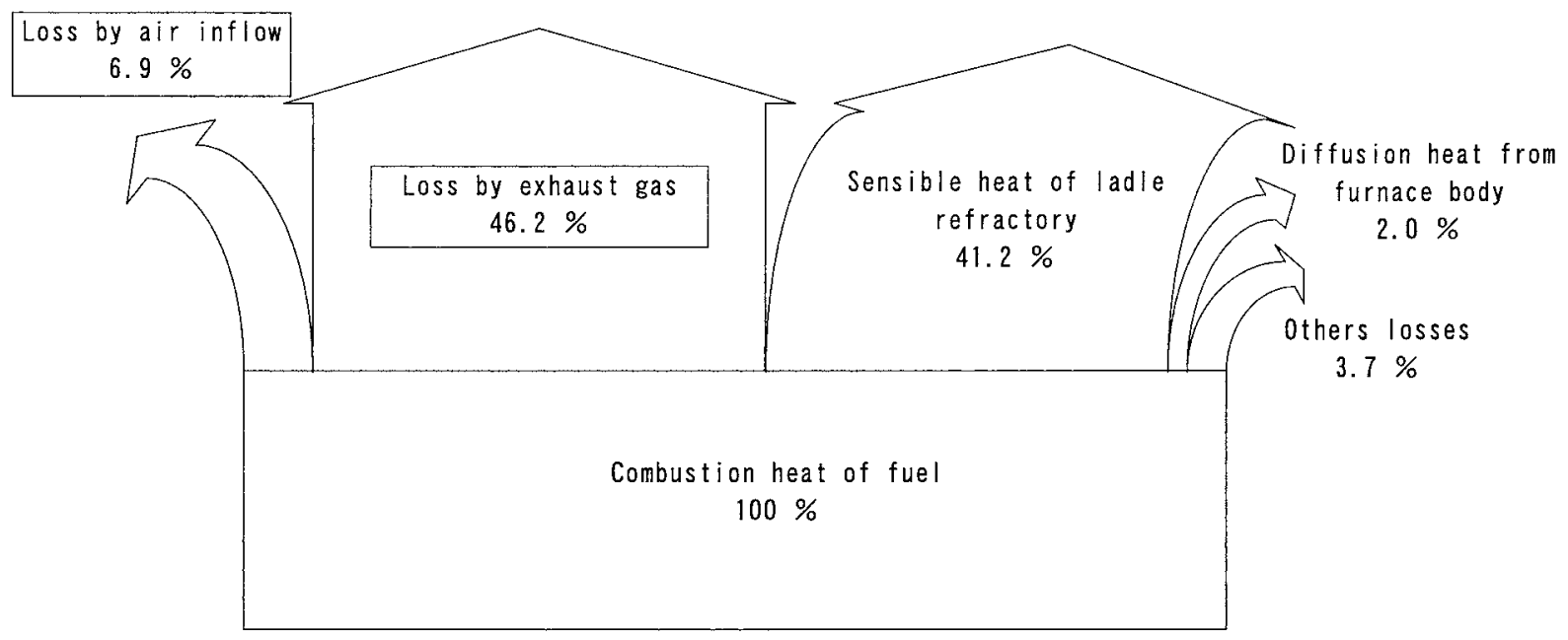

Fig.6. Heat balance of conventional ladle preheater. 


\section{4. 対 策}

\section{1 設備の改善点}

現状の取鍋予熱装置において燃焼効率を改善するため には排ガス熱の再利用による燃焼エアーの予熱, 適切な燃 焼管理，そして侵入エアーの防止が必要である。そこで今 回, Table 2 に示すようにシングル型リジェネバーナーを 導入して排ガス熱を再利用した燃焼エアーの予熱, 自動燃 焼制御システムによる適切な取鍋の予熱を行うことによ る熱口又低減, そして予熱蓋に昇降機能を付加して侵入工 アーを防止し燃料使用量削減の改善を図った。

\section{2 シングル型リジェネバーナーの特徴 と仕様}

今回 Fig.7に示すようにバーナーシングルで回転式の蓄 熱帯によりツイン型リジェネバーナーのように燃焼エ アーの切替えを行うことなく排ガスと燃焼エアーの熱交 換が連続して行うことが可能な装置であるシングル型リ ジェネバーナーを導入した。これは設備占有面積において は省スペースであり当社の場合取鍋予熱装置周辺の設置 スペースが非常に限られており, 燃焼エアーの切替えが必 要である従来型のツイン型リジェネバーナーでは配管ス ペースが確保できずに設置が困難なことがあった。イニ シャルコストにおいてはツイン型リジェネバーナーに比 ベてシングル型リジェネバーナーは約 30 \%安価であるこ

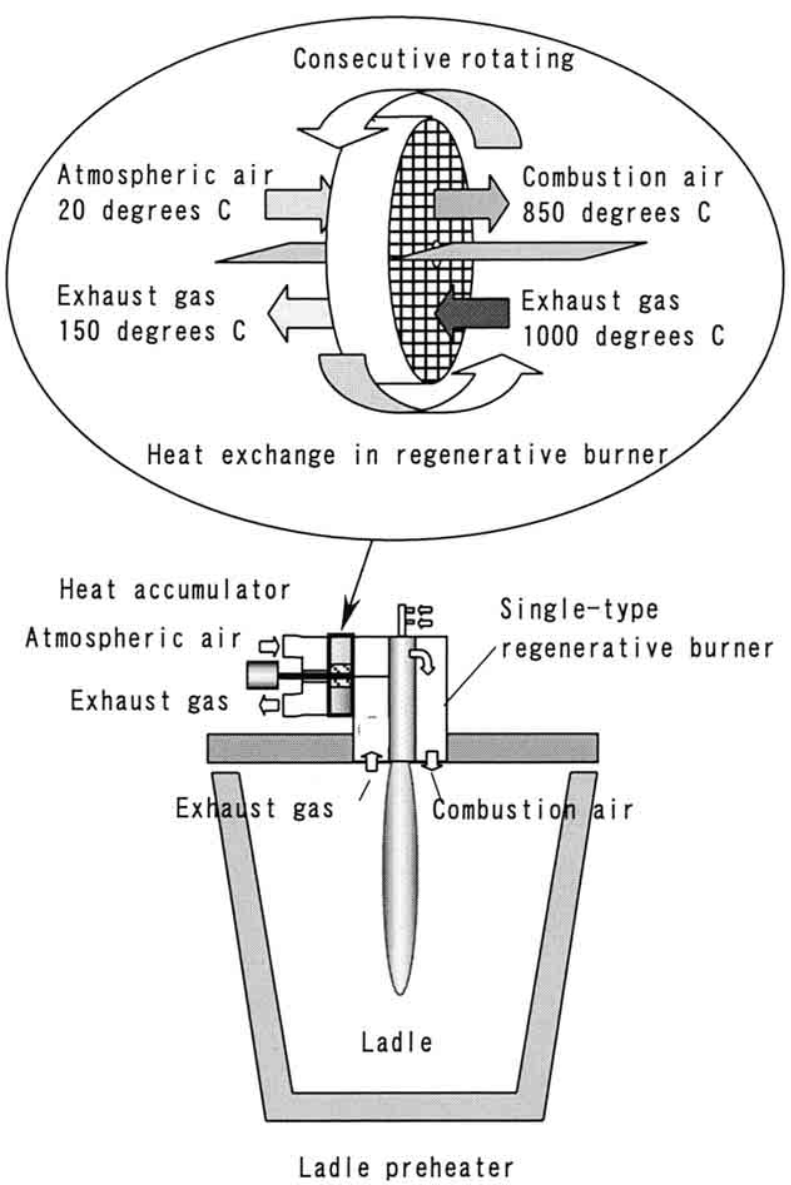

Fig.7. Schematic configuration of single-type regenerative burner.

Table 2. Combustion improvement results of ladle preheater.

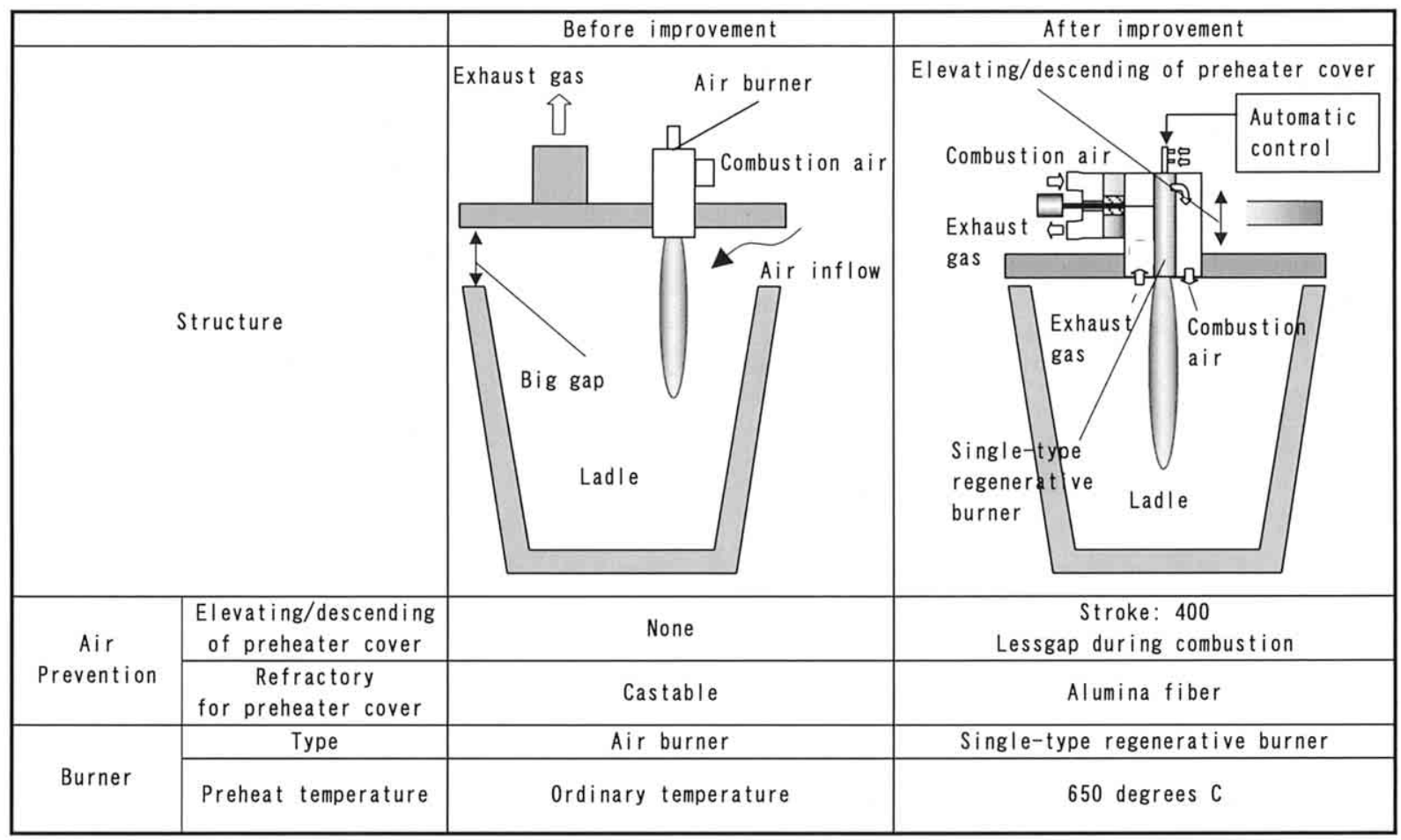




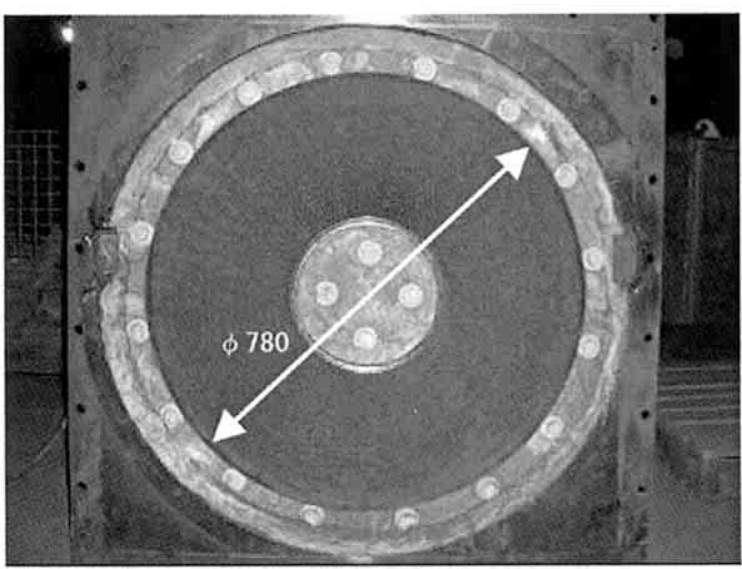

Fig.8. Stainless honeycomb in single-type regenerative burner.

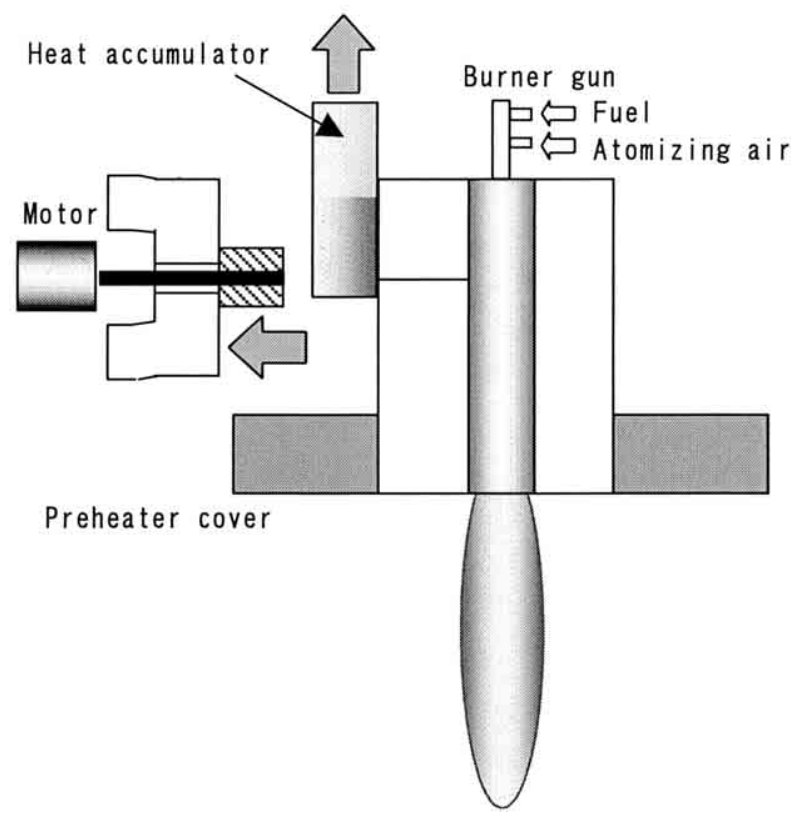

Fig.9. Structure of single-type regenerative burner.

と，そしてメンテナンス性おいては Fig.8 に示すように蓄 熱帯が SUS 製の缶体ハニカムであり，従来のセラミック 八ニカムと比較して壞れにくく, Fig.9 に示すように蓄熱 体の取り出しもセラミックハニカムと比較して容易であ り，交換するときの工数が少なくすむメリットがある．設 備仕様を Table 3 に示す. 型式は縦型上部燃焼一方焚き, 被加熱物である取鍋は $\phi 3600 \mathrm{~mm} \times \mathrm{H} 3850 \mathrm{~mm}$, バーナー 容量は排ガス熱回収により燃焼エアーを常温から最大 650 ${ }^{\circ} \mathrm{C}$ まて予熱する効果を考慮し $4.47 \times 10^{7} \mathrm{~J} / \mathrm{h}$ と従来と比較 して $\triangle 34 \%$ とした. 使用燃料はリジェネバーナーハニカ ムへの酸露点などの影響を考慮し重油から灯油に変更し た。予熱最大温度は $1200{ }^{\circ} \mathrm{C}$, 予熱時間は各取鍋種類によ り 1 ～ 12 時間である.従って今回シングル型リジェネバー ナーを採用した，その比較を Table 4 に，外観を Fig.10に

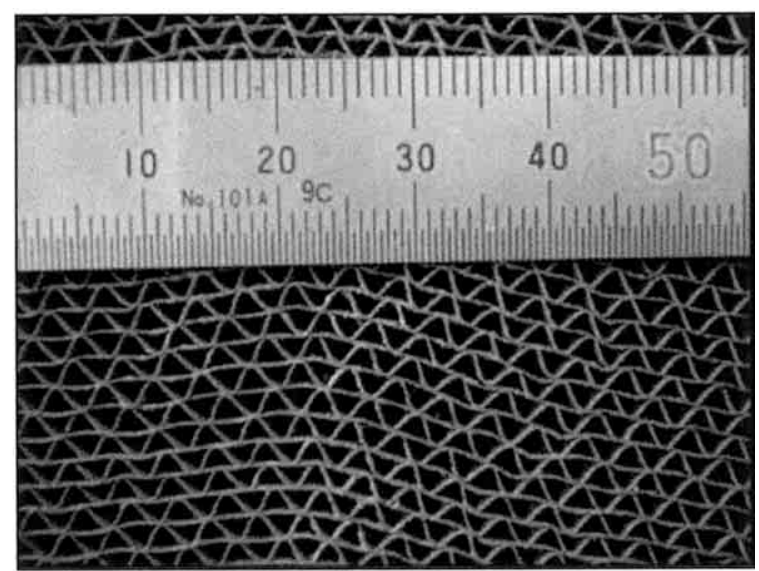

Table 3. Comparison between single-type and twin-type regenerative burners.

\begin{tabular}{l|l}
\hline Type & $\begin{array}{l}\text {-Vertical } \\
\text {-Top burner }\end{array}$ \\
\hline Ladle size & $\$ 3600 \mathrm{~mm} \times \mathrm{H} 3850 \mathrm{~mm}$ \\
\hline Burner capacity & $4.47 \times 10^{7} \mathrm{~J} / \mathrm{h}$ \\
\hline Fuel & Kerosene \\
\hline Preheat temperature & Max. 1200 degrees $\mathrm{C}$ \\
\hline Preheat time & $\begin{array}{l}\text { Cold ladle }: 12 \mathrm{~h} / \text { ladle } \\
\text { Hot ladle }: 1 \mathrm{~h}, 6 \mathrm{~h} / \text { ladle }\end{array}$ \\
\hline
\end{tabular}

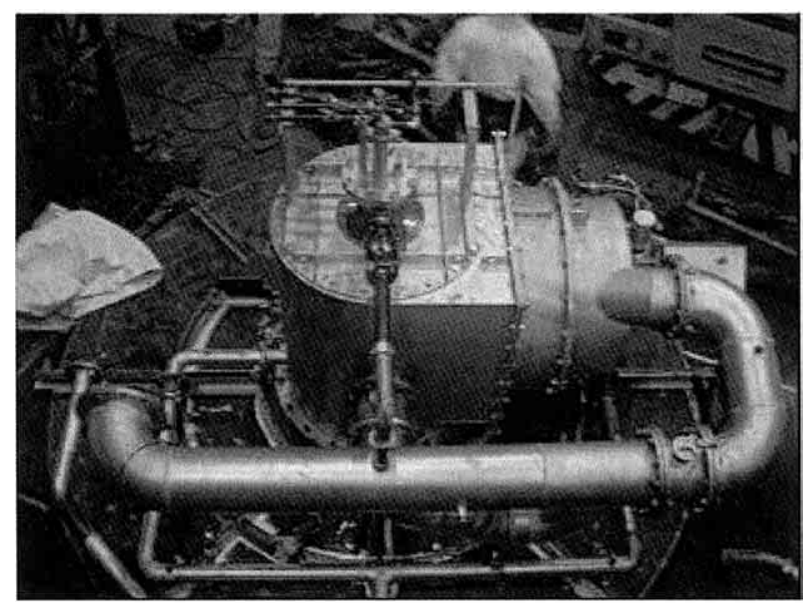

Fig.10. Single-type regenerative burner.

示す.

\section{3 燃焼自動制御と侵入エアーの防止}

取鍋内温度は取鍋蓋に熱電対を設置することにより設 定した目標温度に対して燃料使用量を自動制御すること によりコントロールし，燃料使用量の削減を実施した。ま た, 燃焼開始と同時に取鍋予熱蓋を下げることにより侵入 エアーによる熱ロスを削減し, 適切な燃焼を行うことがで きるように改善した。 


\section{5. まとめ}

今回シングル型リジェネバーナー並びに燃焼自動制御 を導入し, 取鍋予熱装置の燃焼改善を行ったことにより燃 焼の最適化を図ることができ, Fig.11に示すように燃料原 単位の改善を図ることができた，原単位改善量は $\triangle 38 \%$ と大きな効果を示している.ただしこの值は生産量による
ところが大きいので熱精算を実施した，その結果，Fig.12 に示すように排ガス損失は $46.2 \%$ から $29.8 \%$ に, 予熱蓋 隙間からの侵入エアーによる損失は $6.9 \%$ から $4.7 \%$ に減 少し, 使用する燃料も従来に比較して $82.3 \%$ に減少した. 今後, 他の取鍋予熱装置にも今回実施した改善内容の導 入を展開していく.

Table 4. Specification of ladle preheater with single-type regenerative burner.

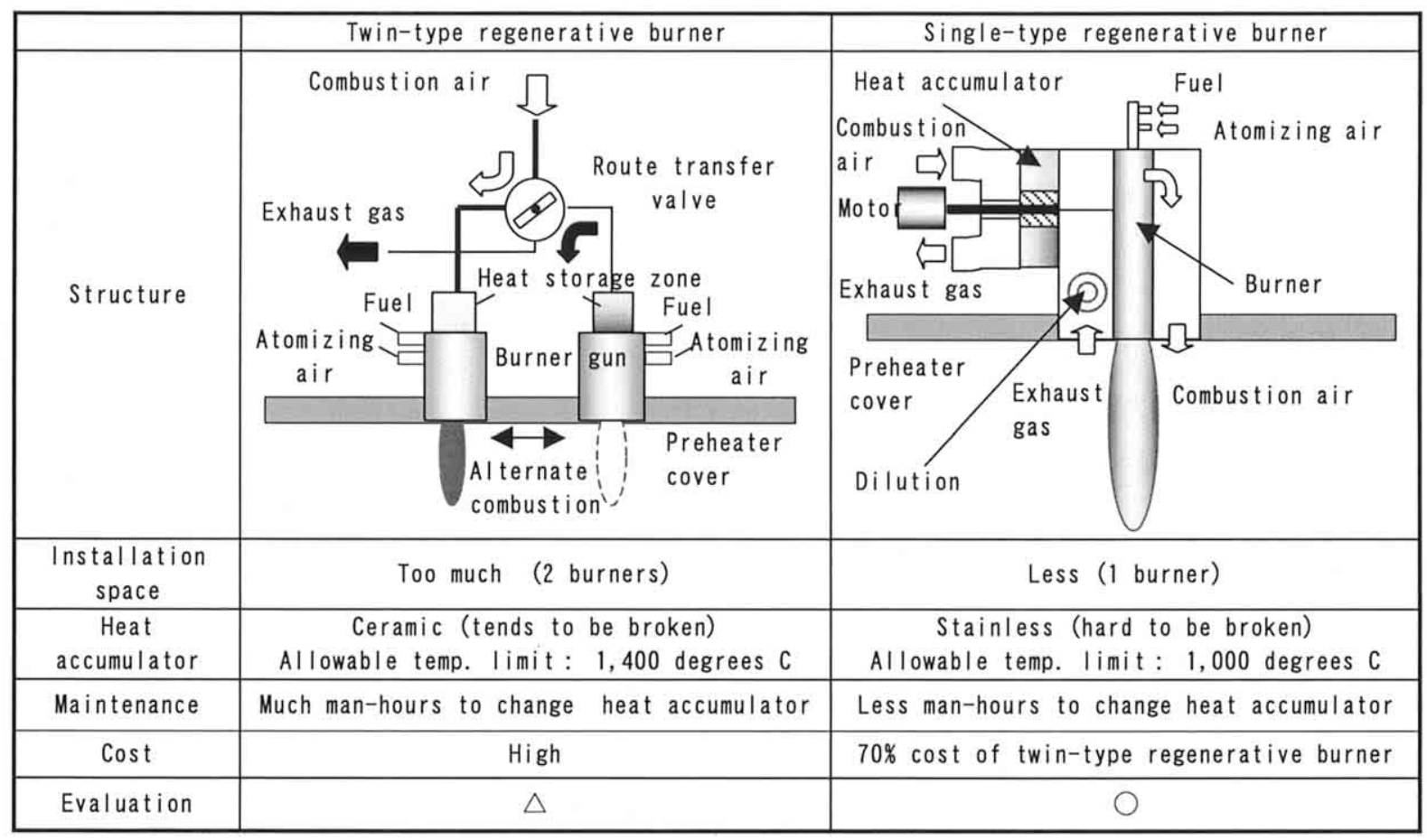

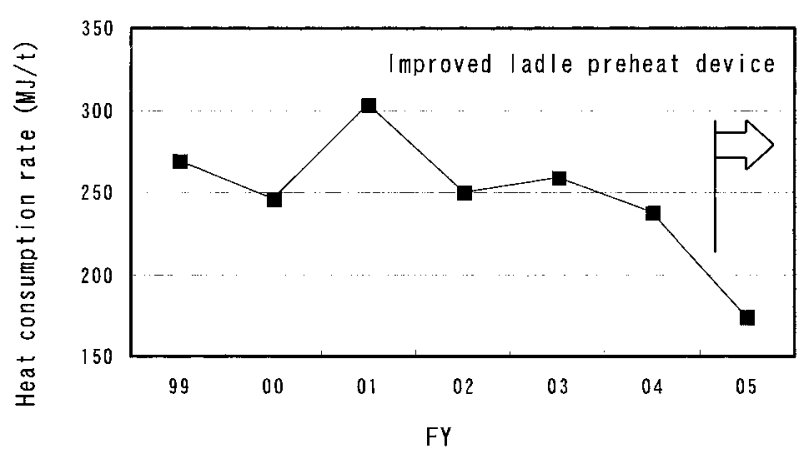

Fig.11. Fuel consumption of ladle preheater with single-type regenerative burner. 


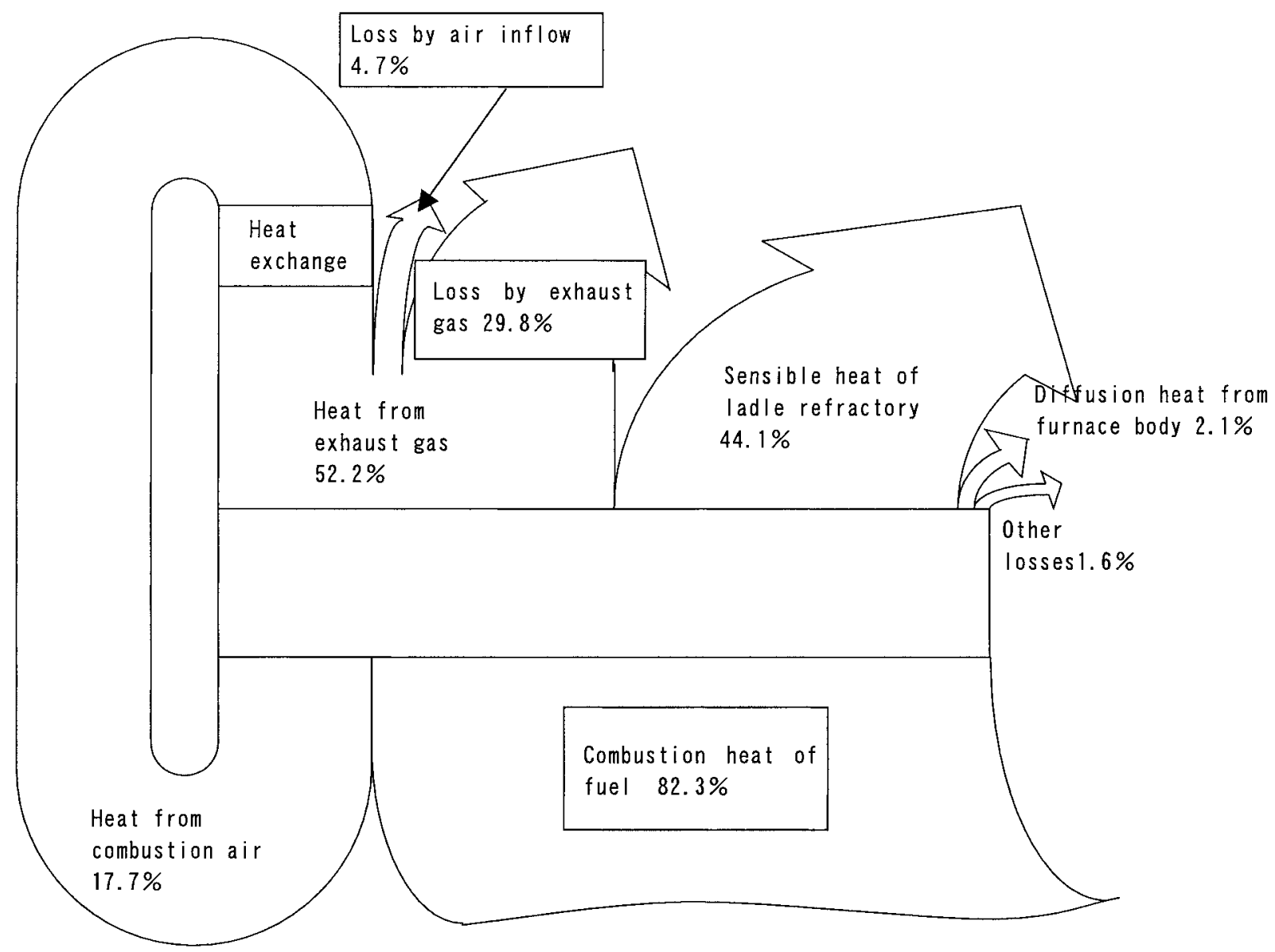

Fig.12. Heat balance of ladle preheater with single-type regenerative burner. 